University of Nebraska - Lincoln

DigitalCommons@University of Nebraska - Lincoln

Ralph Skomski Publications

Research Papers in Physics and Astronomy

September 1992

\title{
GAS PHASE INTERSTITIAL MODIFICATION OF RARE-EARTH INTERMETALLICS
}

J.M.D. Coey

Trinity College, Dublin, Ireland

Ralph Skomski

University of Nebraska-Lincoln, rskomski2@unl.edu

S. Wirth

Trinity College, Dublin, Ireland

Follow this and additional works at: https://digitalcommons.unl.edu/physicsskomski

Part of the Physics Commons

Coey, J.M.D.; Skomski, Ralph; and Wirth, S., "GAS PHASE INTERSTITIAL MODIFICATION OF RARE-EARTH INTERMETALLICS" (1992). Ralph Skomski Publications. 1.

https://digitalcommons.unl.edu/physicsskomski/1

This Article is brought to you for free and open access by the Research Papers in Physics and Astronomy at DigitalCommons@University of Nebraska - Lincoln. It has been accepted for inclusion in Ralph Skomski Publications by an authorized administrator of DigitalCommons@University of Nebraska - Lincoln. 
GAS PHASE INTERSTITIAL MODIFICATION OF RARE-EARTH INTERMETALLICS

J.M.D. Coey, R.Skomski, and S. Wirth

Department of Pure and Applied Physics, Trinity College, Dublin 2, Ireland

\begin{abstract}
The gas phase Interstitial modification of rare-earth Intermetallics is studied. Net reaction energies for nitrogen in $\mathrm{Sm}_{2} \mathrm{Fe}_{17}$ and $\mathrm{Nd}\left(\mathrm{Fe}_{11} \mathrm{TI}\right)$ are $U_{0}=-57 \mathrm{~kJ} / \mathrm{mole}$ and $\mathbf{U}_{0}=-51 \mathrm{~kJ} / \mathrm{mole}$, respectively. The equilibrium nitrogen concentration is calculated as function of temperature and gas pressure using a simple lattice gas model.

For nitrogen in $\mathrm{Sm}_{2} \mathrm{Fe}_{17}$, refined diffusion parameters $D_{0}(N)=1.02 \mathrm{~mm}^{2} / \mathrm{s}$ and $E_{a}(N)=133$ $\mathrm{kJ} / \mathrm{mole}$, determined by thermopiezlc analysis of the Initial stage of nitrogen absorption, are used to calculate nitrogen profles and the time dependence of the mean nitrogen content during nitrogenation. Similiar values are obtained for nitrogen in Nd(Fe11Ti), whereas the activation energles for hydrogen in $\mathrm{Sm}_{2} \mathrm{Fe}_{17}$ and $\mathrm{Nd}\left(\mathrm{Fe}_{11} \mathrm{Ti}\right)$ are $31 \mathrm{~kJ} / \mathrm{mole}$ and $45 \mathrm{~kJ} / \mathrm{mole}$, respectively.

The elastic stress and strain proflles during nitrogenation are calculated. Important results are a large unlaxial strain near the surface of nonuniformily nitrided particles, and core expansion even In the absence of any nitrogen there. Curie temperature and $K_{1}$ profiles are calculated and suggestlons are made regarding the influence of stress on coercivity and disproportionation of the material.
\end{abstract}

\section{INTRODUCTION}

Since the discovery that nitrogen can be introduced into $\mathrm{Sm}_{2} \mathrm{Fe}_{17}$ from the gas to form new interstitial nitrides $\mathrm{Sm}_{2} \mathrm{Fe}_{17} \mathrm{~N}_{3-8}$ with useful hard magnetic properties [1], extensive studies of the structure, intrinsic magnetic properties, hysteresis and electronic structure of 2:17 nitrides have been published [1-9].

Nitrogen typically occupies octahedral interstitial sites in these compounds, coordinated by two rare-earth and four iron atoms. In $\mathrm{Sm}_{2} \mathrm{Fe}_{17}$, the interstitial site is the 9e site shown in Fig. 1, and the ideal composition is $\mathrm{Sm}_{2} \mathrm{Fe}_{17} \mathrm{~N}_{3}$. The nitride has the same crystal symmetry as the parent compound (space group R3m), but the unit cell volume is expanded by about $6 \%$. Usually, the $9 e$ sites are not fully occupied, hence the practice of writing the formula as $\mathrm{Sm}_{2} \mathrm{Fe}_{17} \mathrm{~N}_{3-\delta}$.

Gas-phase nitrogenation has been extended to other structural families of rare-earth intermetallics, e.g. $\mathbf{R}\left(\mathrm{Fe}_{11} \mathrm{Ti}\right) \mathrm{N}$. Carbon can equally well be introduced by gas phase reaction using hydrocarbon gas [2].

From the point of view of iron magnetization, the dramatic effect of the interstitial atoms is"a large increase in Curie temperature ( from $389 \mathrm{~K}$ to $749 \mathrm{~K}$ for $\mathrm{Sm}_{2} \mathrm{Fe}_{17} \mathrm{~N}_{3-8}$ ), due to the dilation of the lattice. Additionally, the interstitial

Manuscript received February 17, 1992

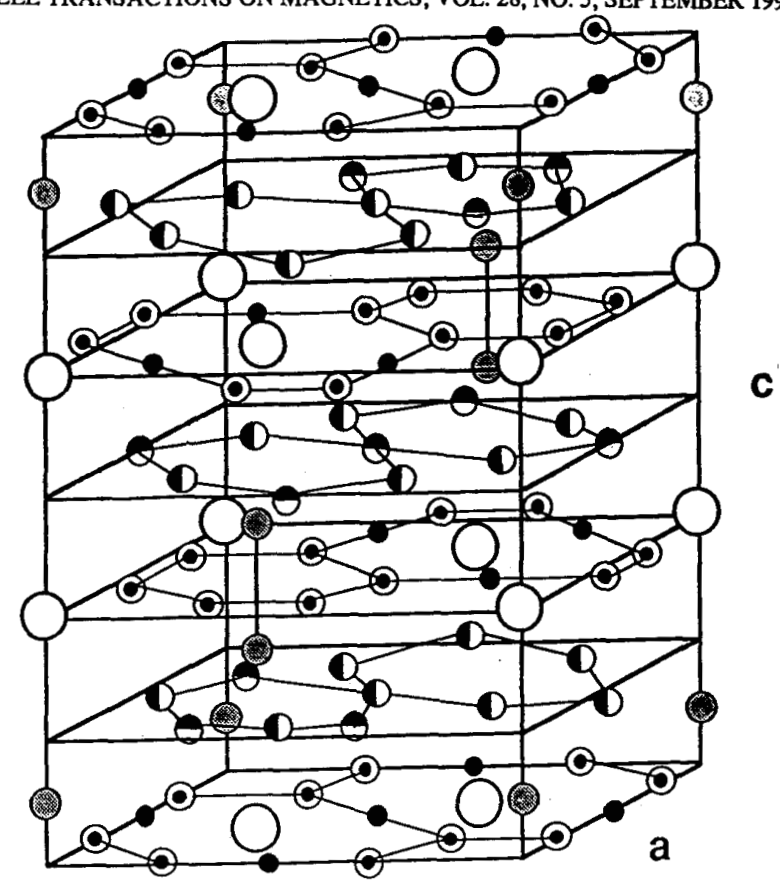

a

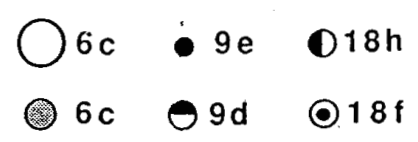

Fig.1. Crystal structure of $\mathrm{Sm}_{2} \mathrm{Fe}_{17} \mathrm{~N}_{3}$. Sm occupies $6 \mathrm{c}$ sites, $\mathrm{N}$ occupies $9 \mathrm{e}$ sites, and the other sites are occupied by Fe.

atoms modify the crystal field at the rare earth sites. An good example is $\mathrm{Sm}_{2} \mathrm{Fe}_{17} \mathrm{Z}_{3}-\delta$ with $\mathrm{Z}=\mathrm{N}, \mathrm{C}$ which shows strong uniaxial anisotropy in contrast to the easy-plane anisotropy of pure $\mathrm{Sm}_{2} \mathrm{Fe}_{17}[1,2]$.

Gas-phase nitrogenation is typically conducted at 400 - $500{ }^{\circ} \mathrm{C}$ on finely-ground $\mathrm{R}_{2} \mathrm{Fe}_{17}$ powder in a pressure of about 1 bar $\mathrm{N}_{2}$, or nitrogen-containing gas such as $\mathrm{NH}_{3}$. At these temperatures the gas-solid reaction proceeds by thermally activated bulk diffusion within the particles. Diffusion kinetics are sluggish at typical nitrogenation temperatures, but if the temperature is increased a competing disproportionation reaction of the $\mathrm{Sm}_{2} \mathrm{Fe}_{17} \mathrm{~N}_{3}$ nitride intervenes $[1,3]$.

Hydrogen has long been known as an interstitial in rare-earth intermetallics. At temperatures of about $250^{\circ} \mathrm{C}$ hydrogen gas easily reacts with $\mathrm{Sm}_{2} \mathrm{Fe}_{17}$, but the hydride remains easy-plane with much less increase in Curie temperature [9].

In order to understand the gas phase interstitial modification process we first examine the quasi-equilibrium properties of $\mathrm{Sm}_{2} \mathrm{Fe}_{17} \mathrm{Z}_{y}$ and $\mathrm{Nd}\left(\mathrm{Fe}_{11} \mathrm{Ti}\right) \mathrm{Z}_{x}$ with $\mathrm{Z}=\mathrm{N}, \mathrm{C}, \mathrm{H}$. Important factors are the binding between interstitial atoms and metal lattice, the temperature and pressure dependence of the maximum nitrogen content, and the spatial distribution of the interstitial atoms. 
Then we present and discuss the diffusion parameters $E_{2}$ and $D_{0}$ for the diffusion of nitrogen and hydrogen in $\mathrm{Sm}_{2} \mathrm{Fe}_{17}$ and $\mathrm{Nd}\left(\mathrm{Fe}_{11} \mathrm{Ti}\right)$. The values for nitrogen are used to calculate nitrogen concentration profiles and the time dependence of the mean nitrogen content during nitrogenation. Finally, we discuss the influence of the inhomogeneous nitrogen concentration, and the corresponding mechanical stress and strain profiles, on the magnetic properties of the nitride.

\section{THE GAS-SOLID REACTION}

\section{Interaction between interstitial atoms}

A key question is whether the quasi-equilibrium nitride is a simple gas-solid solution with contineous range of intermediate nitrogen contents or a two-phase mixture of nitrogen-poor $\alpha-\mathrm{Sm}_{2} \mathrm{Fe}_{17} \mathrm{~N}_{\mathrm{y}}$ and nitrogen-rich $\beta$ -

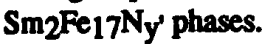

There are two energies involved: the net reaction energy $U_{0}$ and the interatomic long-range interaction $U_{1}$. Phase segregation occurs below a critical temperature $T_{c}$ and is due to attractive interaction $U_{1}$ caused by the lattice deformation around the interstitial atoms [13]. Below $\mathrm{T}_{c}$ the attractive interaction dominates and the interstitial atoms form macroscopic clusters, which shapes the thermodynamic and magnetic properties of the nitride (Fig. 2.). To avoid the coexistence of easy-plane $\alpha$ and casy-axis $\beta$ phases, nitrogenation has to be carried out above $T_{c}$. Quenching may be used to fix the nitrogen distribution.

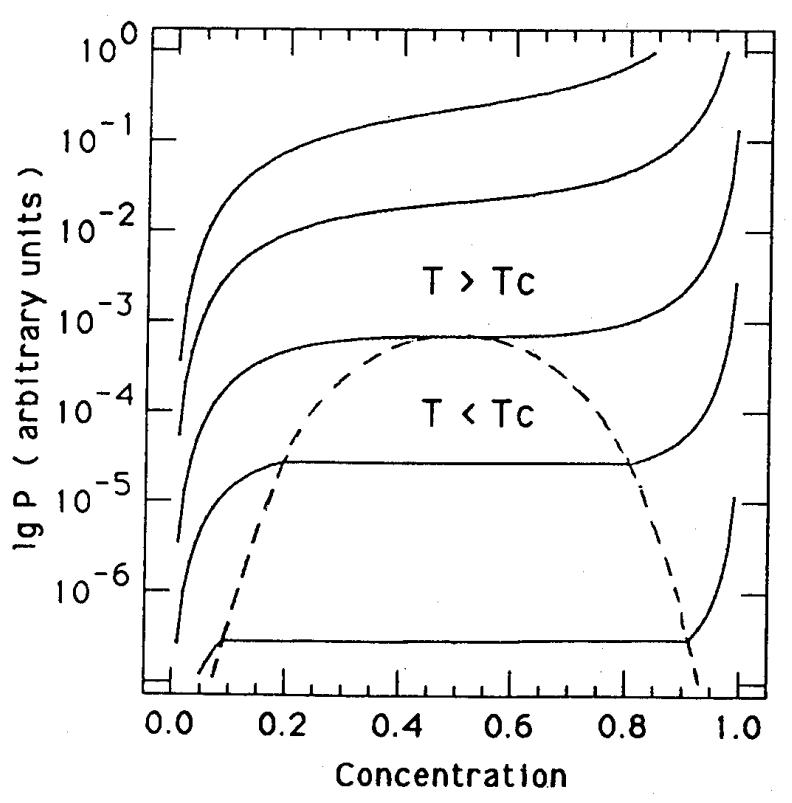

Fig.2.Schematic phase dingram for $\mathrm{Sm}_{2} \mathrm{Fe}_{17} \mathrm{~N}_{\mathrm{y}}$. Below $\mathrm{T}_{\mathrm{c}}$ two phases can be distinguished.

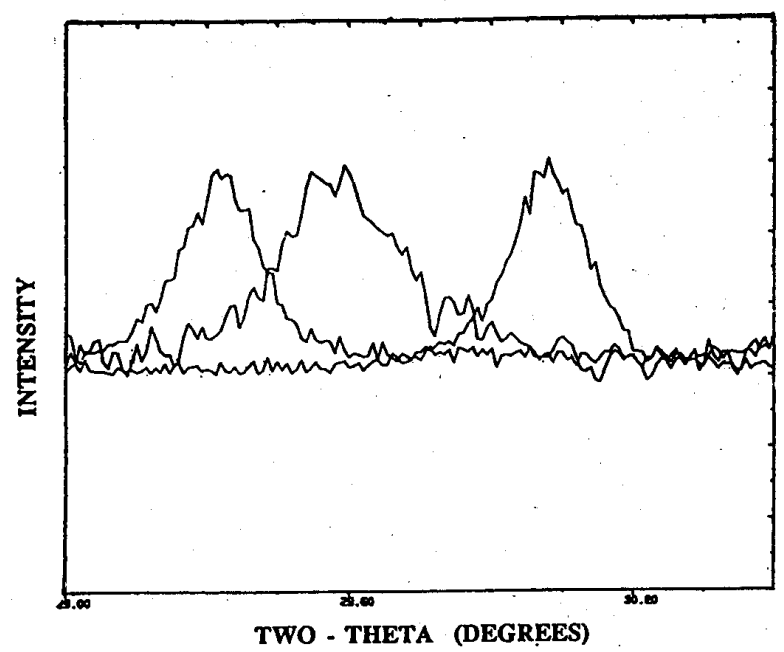

Fig. 3. (113) X-ray diffraction lines for different $\mathrm{Sm}_{2} \mathrm{Fe}_{17} \mathrm{~N}_{\mathbf{y}}$ samples. From right to left: pure $\mathrm{Sm}_{2} \mathrm{Fe}_{17}$, nitrogenated at 500 ${ }^{\circ} \mathrm{C}$ and 13 mbar, nitrogenated at $500^{\circ} \mathrm{C}$ and 1 bar.

At present, all available definitive experiments indicate a low $\mathrm{T}_{\mathrm{c}}$ so that $\mathrm{Sm}_{2} \mathrm{Fe}_{17} \mathrm{~N}_{\mathrm{y}}$ is a gas-solid solution at typical nitrogenation temperatures [10]. In particular it is possible to prepare samples with intermediate lattice parameters which are typical for gas-solid solutions. The intermediate X-ray diffraction peak in Fig. 3. was obtained at $500{ }^{\circ} \mathrm{C}$ and corresponds to the nominal composition $\mathrm{Sm}_{2} \mathrm{Fe}_{17} \mathrm{~N}_{\mathrm{y}}$ with $\mathrm{y} \approx 1.8$. Note that long-time annealing ( $87 \mathrm{~h}$ at $300{ }^{\circ} \mathrm{C}$ ) does not change the situation. At temperatures below $300^{\circ} \mathrm{C}$ the nitrogen diffusivity is too low to get definitive information within reasonable measurering times.

The interatomic interaction $U_{1}$ is proportional to the concentration of the interstitial atoms in the lattice and to the square of the lattice expansion $\Delta v$ per interstitial atom [13]. Table I shows that $\Delta v$ for nitrogen is larger than for hydrogen. On the other hand, comparing the nominal compositions of $\mathrm{Sm}_{2} \mathrm{Fe}_{17} \mathrm{~N}_{3}$ and the classical gas-solid system palladium hydride $\mathrm{PdH}$ with $\mathrm{T}_{\mathrm{c}}=565 \mathrm{~K}$ [11] there are more than six times fewer gas atoms per metal atom in the nitride. A $T_{c}$ estimation for $\mathrm{Sm}_{2} \mathrm{Fe}_{17} \mathrm{~N}_{\mathrm{y}}$ which takes into account this dilution effect yields a value of about room temperature [12].

We now neglect the interatomic interaction and model the $\mathrm{Sm}_{2} \mathrm{Fe}_{17} \mathrm{~N}_{\mathrm{y}}$ system as an ideal gas-solid solution with $\mathrm{U}_{0}$ negative and $\mathrm{U}_{1}=0$.

\section{Equilibrium nitrogen concentrations}

The solubility of gases in metals is determined by two factors. One one hand, the gas tends to occupy interstitial sites if they are energetically favourable, i.e. if $U_{0}<0$. On the other hand, thermal activation tends to create disorder in the gas-solid system. In the extreme high temperature limit, $k T \gg U_{0}$, this dominates the binding interaction and the solubility approaches a low, energy-independent value when 




Fig.4. Schematic illustration of the lattice gas model, showing nitrogen in the gas phase (left) and in solid solution in the intermetallic compound ( right ).

all phase space configurations have the same probability.

Nitrogen in $\mathrm{R}_{2} \mathrm{Fe}_{17}$ shows a large solubility even at moderately elevated temperatures. At $500{ }^{\circ} \mathrm{C}$ and 1 bar nitrogen pressure the majority of all octhedral sites are occupied [1,3], which indicates a strong gas-metal binding.

To investigate the gas-solid reactions

$$
\frac{1}{2} \mathrm{yZ}_{2}[\mathrm{~g}]+\mathrm{R}_{2} \mathrm{Fe}_{17}[\mathrm{~s}] \Leftrightarrow \mathrm{R}_{2} \mathrm{Fe}_{17} \mathrm{Z}_{\mathrm{y}}[\mathrm{s}]
$$

and

$$
\frac{1}{2} y Z_{2}[g]+R\left(F e_{11} T i\right)[s] \Leftrightarrow R\left(\mathrm{Fe}_{11} \mathrm{Ti}\right) \mathrm{N}_{\mathrm{y}}[\mathrm{s}]
$$

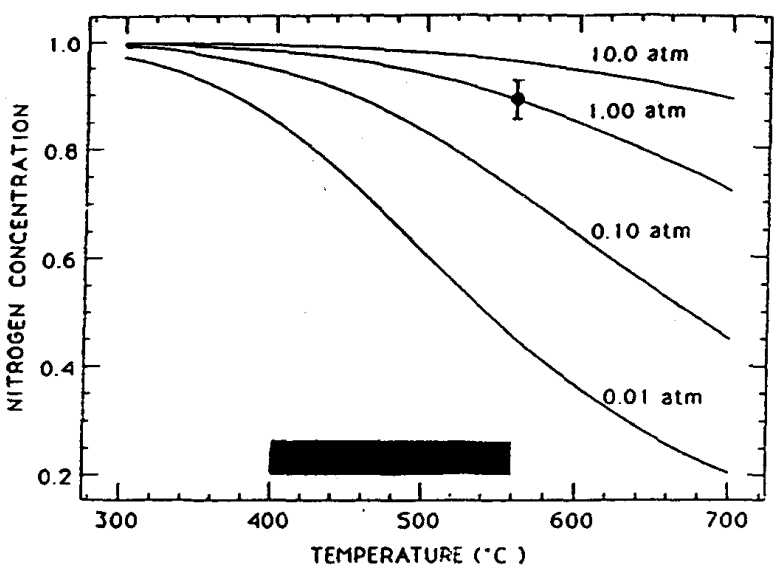

Fig. 5. Equilibrium nitrogen concentrations in $\mathrm{Sm}_{2} \mathrm{Fe}_{17}$ as function of temperature and pressure. The black bar shows the temperature region where nitrogenation may be carried out. a lattice-gas model is used, which consists of a solid with $\mathbf{n}_{\mathbf{g}}$ octahedral sites in contact with a large but constant volume of gas $V$ divided into $N_{0}=V / V_{0}$ cubic cells [Fig. 4.]. $V_{0}$ is the cube of the atomic diameter of molecular nitrogen, 1.33 $\AA^{3}$. The partition function for the corresponding gas-solid equilibrium can be calculated, yielding the equation of state

(1)

$$
c_{0}=\left(1+\sqrt{\frac{G T T}{V_{0} P}} e^{U_{0} / k T}\right)^{-1}
$$

with being $c_{0}$ the number of nitrogen atoms per interstitial site. Details of the calculation are given in [10]. Note that Eq. (1) was used to predict the position of the intermediate peak in Fig. 3.

The values $U_{0}=-57 \pm 5 \mathrm{~kJ} / \mathrm{mole}$ and $U_{0}=-51 \pm 10$ $\mathrm{kJ} /$ mole for $\mathrm{Sm}_{2} \mathrm{Fe}_{17}$ and $\mathrm{Nd}\left(\mathrm{Fe}_{11} \mathrm{Ti}\right)$, respectively, were derived from long-time isothermal absorption experiments, using Eq. (1). For hydrogen in $\mathrm{Y}_{2} \mathrm{Fe}_{17}$ (octahedral interstices) an energy of $U_{0}=-35 \pm 15 \mathrm{~kJ} / \mathrm{mole}$ is obtained. Typical $\operatorname{co}(T, p)$ curves for nitrogen in $\mathrm{Sm}_{2} \mathrm{Fe}_{17}$ calculated from Eq. (1) are shown in Fig. 5. The experimentally accessible zone where equilibrium can be achieved without disproportionation within a reasonable time is shown by the black box. These curves can serve as guide for preparing nitrides of a desired composition.

\section{The energy balance}

The net reaction energy $U_{0}$ consists of three parts: the energies which are necessary to dissociate the gas molecules and to expand the lattice, and the energy gain due to the gaslattice interaction.

The simplest approximation which can be made in order to explain binding energy and lattice expansion is to treat the metallic nitride as free electron gas. Assuming a positively charged ion core $Z^{+}$with radius $R_{C}$ in a pure electron region with radius $R$, the quasi-equilibrium ground state energy $U$ can be calculated in lowest order perturbation theory. Minimization of $U$ with respect to $R$ yields a lattice

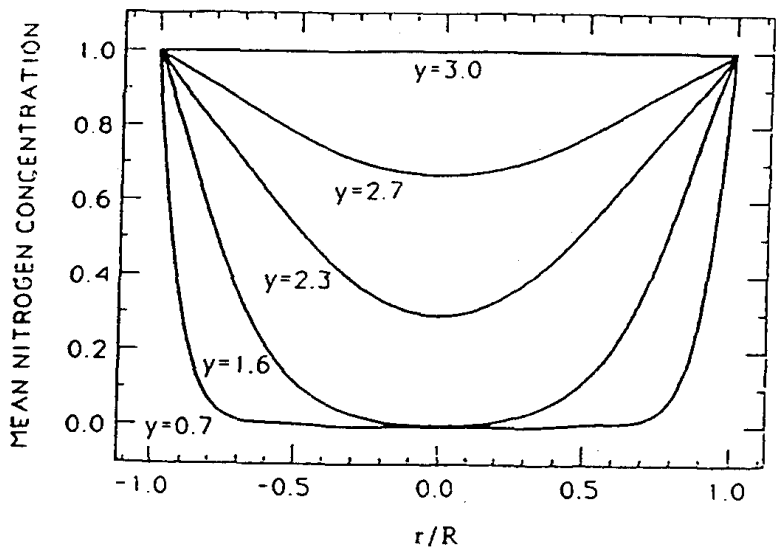

Fig.6. Nitrogen concentration profiles for spherical particles. The equilibrium nitrogen content is taken as $\mathbf{3 . 0}$. 
-independent value $\mathbf{R}_{\mathbf{0}}$, which can be interpreted as "metallic radius" of the interstitial atom. Values for $\mathbf{R}_{c}$ and $\boldsymbol{\Omega}_{0}=$ $4 \pi R_{0} 3 / 3$ are given in Table $I$. The values of $\Omega_{0}$, which greatly exceed the corresponding covalent volumes, can be identified with the experimental lattice expansion $\Delta v$.

\section{TABLE I : VOUUME EXPANSION PER INIERSTIIALSTIE}

$\begin{array}{lrrc}\text { System } & R_{c}[A] & \Omega_{0}\left[A^{3}\right] & \Delta v\left[A^{3}\right] \\ & & & \\ \text { Sm}_{2} \mathrm{Fe}_{17} \mathrm{~N}_{y} & 0.55 & 4.88 & 6.3 \\ \mathrm{Sm}_{2} \mathrm{Fe}_{17} \mathrm{C}_{y} & 0.60 & 5.30 & 7.3 \\ \text { Sm2Fe17 }_{\mathbf{y}} & 0.00 & 2.67 & 3.0\end{array}$

From hydrogen in metals [11], which generally shows an expansion $\Delta v=2.9 A^{3}$, the rule is known that the ionic character of the gas-metal binding increases with hydrogen content and difference in electronegativity. Transferring this picture to the 2-17 and 1-12 nitrides, a certain delocalized, "metallic" character of the binding might be expected due to the comparatively low concentration of the octahedral interstices. In any case, the binding between nitrogen and the intermetallic lattice is energetically less favourable than disproportionation of the lattice and the formation of ionic rare-earth nitrides, which represent the real ground state.

The calculation of the net reaction energy $U_{0}$ itself is very difficult. Nitrogen dissociation and gas-lattice exchange interaction yield large energy contributions which are not exactly known and more or less cancel each other. Hence higher order energy contributions due to electrostatic attraction or lattice expansion can tip the scales.

As a rule, gas-phase interstitial modification is possible for small atoms with moderate electronegativity. Large atoms require much energy to deform the lattice around the interstices. This energy can be provided, if the chemical affinity between interstitial atoms and metals atoms is sufficiently strong. A corresponding crude estimation [12] yields the gas-solid reaction condition

$$
\chi_{Z}>1.6+R_{A}(Z)[\AA]
$$

where $\chi_{Z}$ and $R_{A}(Z)$ are the electronegativity and the covalent radius of the interstitial atoms, respectively. However, if the reactivity (electronegativity) of the interstitial atoms is too large, the gas-solid system immediatetly approaches its stable equilibrium state. An example is the reaction with oxygen, which leads to the disproportionation of the intermetallic lattice and to the formation of $\mathrm{Sm}_{2} \mathrm{O}_{3}$.

\section{DIFFUSION OF INTERSTITIAL ATOMS IN $\mathrm{Sm}_{2} \mathrm{Fe}_{17} \mathrm{~N}_{\mathrm{y}}$ AND Nd(Fe11Ti)}

\section{Nitrogen profiles}

At typical nitrogenation temperatures of $400{ }^{\circ} \mathrm{C}-600$ ${ }^{\circ} \mathrm{C}$ the gas-solid reaction time is determined by the bulk diffusion of the interstitial atoms in the intermetallic lattice. Below about $360^{\circ} \mathrm{C}$ the surface reactivity of the metallic particles strongly decreases, and the nitrogenation time is controlled by the nitrogen flux through the particle surface.
Neglecting grain-boundary diffusion in large particles and anisotropic diffusion, nitrogen profiles for typical nitrogenation temperatures are found by solving the diffusion equation

$$
\frac{\partial c}{\partial t}=D \nabla^{2} c
$$

subject to the boundary condition $c\left(r_{S}, t\right)=c_{0}$ at the particle surface.

In systems with $U_{1}=0$ the chemical diffusion constant $D$ is independent of the concentration [14], and for spherical particles the boundary value problem Eq. (3) can be solved analytically [15]. Some typical nitrogen profiles are shown in Fig. 6. Note that apparently well-nitrogenated grains of $\mathrm{Sm}_{2} \mathrm{Fe}_{17} \mathrm{~N}_{2.3}$ consist of a shell with $\mathrm{y}=3$ and small core with $y \approx 1$ only. The reaction time which is necessary to obtain well-nitrogenated particles can be estimated using Fig. 7 [10].

In the case of 2-17 and 1-12 carbides the diffusion constants can be estimated indirectly. Gas-phase carbonation is usually conducted under conditions that are typical for nitrogenation [2]. Hence the diffusion constants of nitrogen and carbon in the must be comparable. Note that nitrogen and carbon atoms have about the same atomic size, and often show comparable diffusivities in metals [11].

\section{Experimental determination of the diffusion constants}

To describe the temperature dependence of the diffusion constant the Armenius equation

$$
D=D_{0} e^{-E_{a} / k T}
$$

is used. Since the short-term absorption of nitrogen is actually independent of particle-shape, we have used shorttime thermopiezic analysis (TPA) measurements to determine

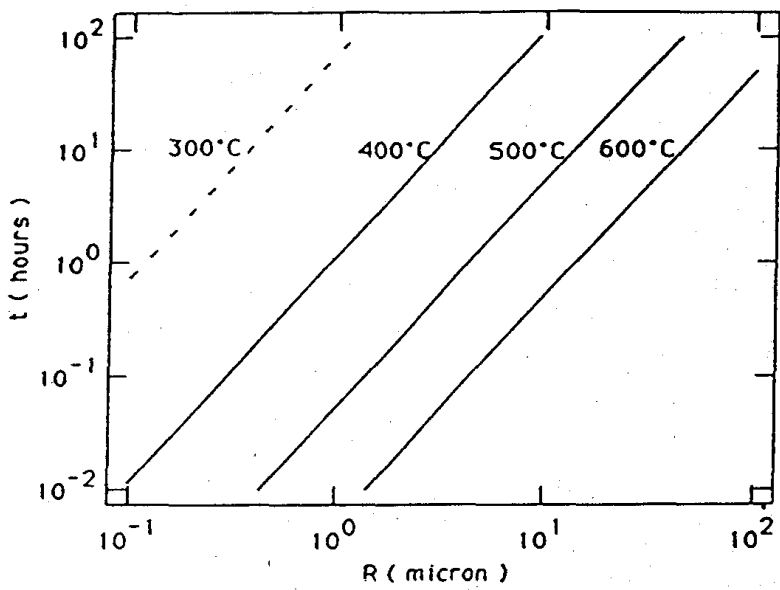

Fig. 7. Approximate nitrogenation time for spherical grains as function of particle radius $\mathbf{R}$ and temperature. 
2336

$E_{\mathrm{a}}$ and $\mathrm{D}_{0}$. The Arrhenius plot Fig. 8, yields an activation energy of $133 \pm 10 \mathrm{~kJ} / \mathrm{mole}$ for nitrogen in $\mathrm{Sm}_{2} \mathrm{Fe}_{17}$. The magnitude of $\mathrm{D}_{0}$ is given by the measured value $1.02 \cdot 10$ - 6 $\mathrm{m}^{2} / \mathrm{s}$. For nitrogen in $\mathrm{Nd}\left(\mathrm{Fe}_{11} \mathrm{Ti}\right)$ values of $\mathrm{E}_{2}=158 \pm 15$ $\mathrm{kJ} /$ mole and $\mathrm{D}_{0}=6.5 \cdot 10^{-6} \mathrm{~m}^{2} / \mathrm{s}$ are obtained.

In the case of hydrogen the accessible temperature window is smaller, which limits the exactness of the results. The measured values are $E_{a}=31 \pm 10 \mathrm{~kJ} /$ mole and $D_{0}=4.4$ - $10-.7 \mathrm{~m}^{2} / \mathrm{s}$ for $\mathrm{Sm}_{2} \mathrm{Fe}_{17}$, and $\mathrm{E}_{\mathrm{a}}=45 \pm 15 \mathrm{~kJ} / \mathrm{mole}$ and $\mathrm{D}_{0}=5.8 \cdot 10^{-7} \mathrm{~m}^{2} / \mathrm{s}$ for $\mathrm{Nd}\left(\mathrm{Fe}_{11} \mathrm{Ti}\right)$, respectively.

The activation energies of hydrogen and nitrogen in $\mathrm{Sm}_{2} \mathrm{Fe}_{17}$ and $\mathrm{Nd}\left(\mathrm{Fe}_{11} \mathrm{Ti}\right)$ are rather large, but can nevertheless be regarded as typical for interstitial diffusion in metals [11].

$D_{0}$ should be of order $a^{2} v_{0}$ where $a$ is the jump distance in the diffusion process, and $v_{0}$ is an attempt frequency $[11,15]$. The estimation $a \propto 3 A$ and $v_{0} \propto 10^{13}$ $\mathrm{s}^{-1}$ yields $D_{0} \propto 1 \cdot 10^{-6} \mathrm{~m}^{2} / \mathrm{s}$. $D_{0}$ values significantly smaller than $1 \mathrm{~mm}^{2} / \mathrm{s}$ correspond to a negative activation entropy, which is physically unreasonable in the present context.

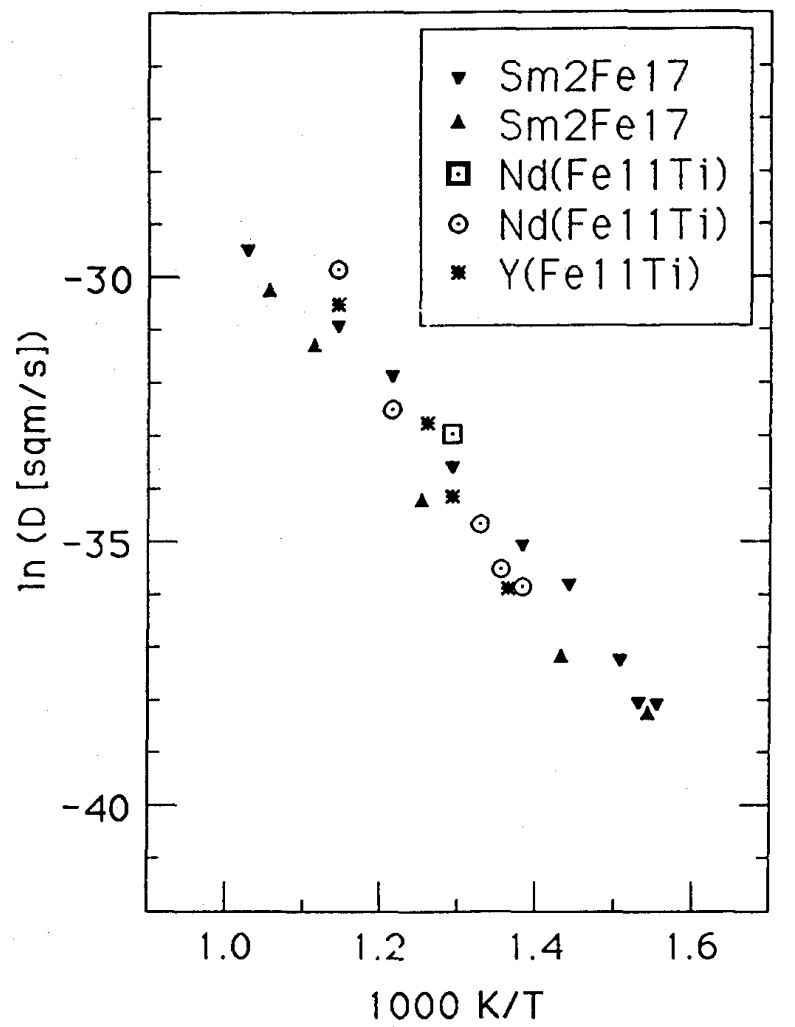

Fig. 8. Armenius plot for the diffusion of nitrogen in $\mathrm{Sm}_{2} \mathrm{Fe}_{17}$ and $\mathrm{Nd}\left(\mathrm{Fe}_{11} \mathrm{Ti}\right)$. Note that there are no main diferences between $\mathrm{Sm}_{2} \mathrm{Fe}_{17}$ and $\mathrm{Nd}\left(\mathrm{Fe}_{11} \mathrm{Ti}\right)$.

\section{MAGNETIC PROPERTIES}

Stress and strain

Inhomogeneous nitrogen profiles cause inhomogeneous mechanical stress and strain profiles, which influences the magnetic properties of the nitride. The nitrogenated outer shell cannot expand freely because it is connected to the un-nitrogenated core. The elastic stress and strain profiles for given nitrogen profiles can be calculated minimizing the elastic energy. For isotropic and coherent lattices which obey Hooke's law, stress and strain profiles can be obtained for spherical and oblate particles $[10,12]$.

Fig. 9. shows the local volume expansion ( $\Delta \mathrm{V} / 3 \mathrm{~V}$ ) and the radial expansion for a spherical particle of $\mathrm{Sm}_{2} \mathrm{Fe}_{17} \mathrm{~N}_{1.6}$. Two striking results are (i) the expansion of the core even in the absence of any nitrogen there, and (ii) the large radial strain near the surface which exceeds the lattice expansion of a fully nitrogenated grain by about $50 \%$.

The strong uniaxial deformation near the surface is likely to intensify the disproportionation of the material into $\alpha$-iron and SmN which destroys coercivity [10]. A possible ways to avoid this surface disproportionation is to begin the nitrogenation at a sufficiently low temperature.

\section{Curie temperature}

The large Curie temperature increase of the nitrides and carbides is mainly due to the expansion of the intermetallic lattice $[1,6]$. In homogeneously nitrogenated grains the lattice expansion can be interpreted as dependent on the local nitrogen concentration. However, in the inhomogeneous case this dependence is modified by the macroscopic strain. Fig. 8 . shows strain and nitrogen profiles of a partly nitrogenated grain with practically no nitrogen at the centre, but significant lattice expansion $\Delta V / V=1.1 \%$.

Taking into account the neasrly linear dependence of the Curie temperature on the lattice expansion, Fig. 9. gives

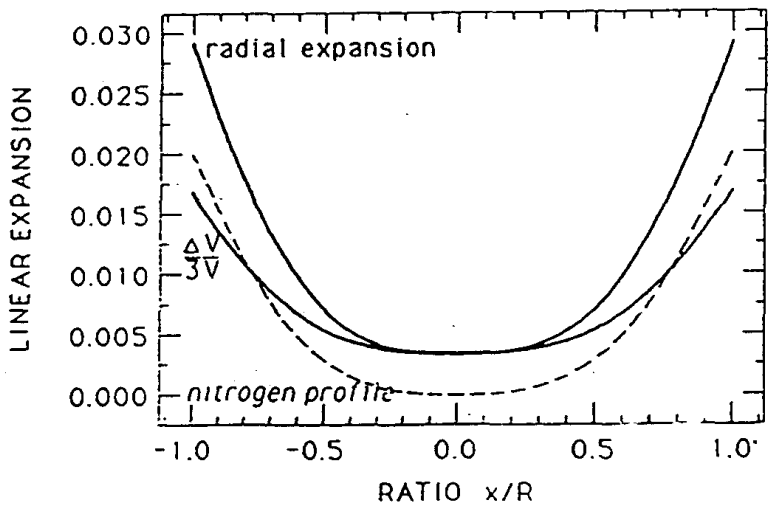

Fig. 9. Radial and volume expansion for a spherical grain of $\mathrm{Sm}_{2} \mathrm{Fe}_{17} \mathrm{~N}_{1.6}$ 


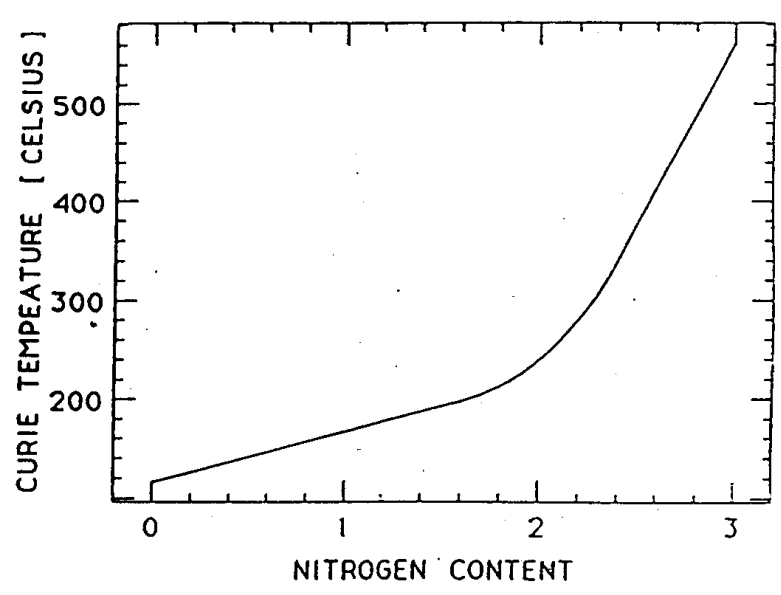

Fig.10 The concentration dependence of the Curie temperature at the centre of a spherical particle.

the Curie temperature at the core of the particle as function of y. An important consequence of the core expansion is the existence of regions with elevated Curie temperature but negative $K_{1}$, the "soft centre" problem.

\section{Anisotropy and coercivity}

The maximum coercivity of a particle depends on the anisotropy constant $K_{1}$. For pure $\mathrm{Sm}_{2} \mathrm{Fe}_{17}, \mathrm{~K}_{1}$ is negative (easy plane) but as nitrogen enters the $9 \mathrm{e}$ sites it creates a strong electric field gradient at the $\mathrm{Sm} 4 \mathrm{f}$ shell. The crystalfield coefficients, $A_{20}$ in particular, are modified and $K_{1}$ -increases. The grain centre is a critical region, because so long as $K_{1}$ remains negative there it will act as a nucleation centre for reverse domains, and hence destroy coercivity. The dependence of $K_{1}(r=0)$ on $y$ is given in Fig. 10. Only particles with $y>2$ can be expected to yield any appreciable coencivity.

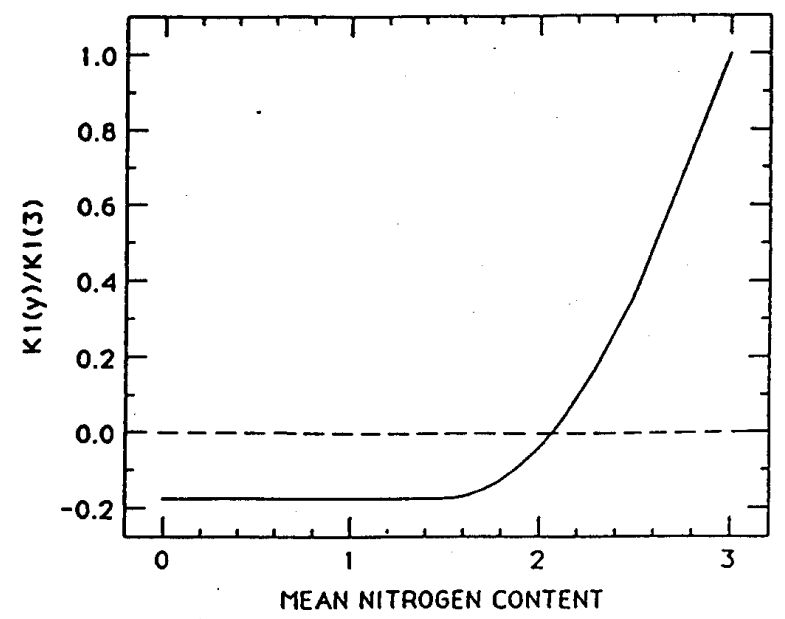

Fig.11 The concentration dependence of the anisotropy constant $K_{1}$ at the centre of a spherical particle

\section{CONCLUSIONS}

We have obtained an equation of state, which is used to calculate the equilibrium nitrogen content as a function of pressure and temperature. Net reaction energies for nitrogen and hydrogen in 2-17 and 1-12 intermetallic compounds are derived and discussed. The volume expansion per atom can be explained using a free electron model.

Nitrogen and hydrogen diffusion in $\mathrm{Sm}_{2} \mathrm{Fe}_{17}$ and $\mathrm{Nd}\left(\mathrm{Fe}_{11} \mathrm{Ti}\right)$ has been examined, and values of $\mathrm{D}_{0}$ and $\mathrm{E}_{\mathrm{a}}$ are derived. The values $D_{0}=1.02 \mathrm{~mm}^{2} / \mathrm{s}$ and $E_{a}=133 \mathrm{~kJ} /$ mole for nitrogen in $\mathrm{Sm}_{2} \mathrm{Fe}_{17}$ have been used to calculate nitrogen concentration profiles and nitrogenation curves.

Stress and strain in inhomogeneously nitrogenated grains have been investigated. Large uniaxial strain near the particle surface is predicted and there is a likely influence of this excess strain on the disproportionation of the nitride and its coercivity.

In the initial stage of nitrogenation, stress and strain lead to an expanded particle centre with increased Curie temperature but negative $K_{1}$. This "soft centre", which is found in particles with average nitrogen contents as high as $y$ $=2$, acts as a nucleation centre and destroys coercivity [16].

\section{ACKNOWLEGDMENTS}

This work forms part of the 'Concerted European Action on Magnets'. It was supported by the BRITE/EURAM Programme of the European Commission.

\section{REFERENCES}

[1] J.M.D. Coey and H. Sun, J.Magn.Magn.Mater.87(1990)L251

[2] J.M.D. Coey, H. Sun, Y. Otani and D.P.F.Hurley, J.Magn.Magn.Mater.98(1991)76

[3] J.M.D. Coey, J.F. Lawler, H. Sun, and J.E.M Allan, J. Appl. Phys.69 (1991)3007

[4] T.W. Capehart, R. K. Mishra, and F.E. Pinkerton, Appl.Phys. Lett. 58(1991)1395

[5] K. Schnitzke, L. Schultz, J. Wecker, and M.Katter, Appl. Phys.Lett. 57(1990) 2853

[6] K.HJ. Buschow, R. Coehoom, D.B. de Mooij, K. de Waard, and T.H. Jacobs, J. Magn. Magn. Mater. 92(1990)L35

[7] O. Isnard, S. Miraglia, J.L. Soubeyroux, J. Pannetier, and D. Fruchart, Phys. Rev. B (1992), (in press )

[8] Y.P. Li, Hong-Shuo Li, and J.M.D. Coey, phys. stat. sol. (b) 166 (1991)K107

[9] Wang Xiang-Zhong et al., Mater. Sci. 23(1988)329

[10] R. Skomski and J.M.D. Coey, to be published

[11] J.D. Fast, Gases in metals Macmillan, London,1976

[12] R. Skomski, unpublished

[13] H. Wagner, and H. Horner, Advan. Phys. 23, 587 (1974)

[14] R. Kuttner, K. Binder, and K.W. Kehr, Phys.Rev.B. 26(1982)2967

[15] B.S. Bochstein, Diffusion in metals [russ.] Metallurgija, Moscow, 1978

[16] R. Skomski et al., to be published 